\title{
Friedreich's Ataxia. Cardiac Evaluation of 25 Patients with Clinical Diagnosis and Literature Review
}

\author{
Lilian Maria José Albano, Silvana Angelina Dório Nishioka, Regina Lucia Moysés, Jaqueline Wagenführ, \\ Débora Bertola, Sofia Mizuho Miura Sugayama, Chong A. Kim
}

São Paulo, SP - Brazil

\begin{abstract}
Objective - Cardiac evaluation (clinical, electrocardiographic and echocardiographic) of 25 Brazilian patients with clinical diagnosis of Friedreich's ataxia (FA) related to the frequency and the size of GAA repeats (unstable expansion of trinucleotide repeats that results in the disease).
\end{abstract}

Methods - Clinical and cardiac study including electrocardiogram and echocardiogram of all patients and molecular analysis to detect the frequency and the size of GAA expansion, by polymerase chain reaction analysis.

Results - Homozygous GAA expansion was detected in 17 patients (68\%) - all typical cases. In 8 (32\%) cases (6 atypical and 2 typical), no GAA expansion was observed, therefore it was not considered Friedreich's ataxia. All patients with GAA expansion (100\%) had electrocardiographic abnormalities, and only $25 \%$ of the cases without GAA expansion had some abnormality on this exam. However, only $6 \%$ of all patients revealed some signals/symptoms suggestive of cardiac involvement.

Conclusion - A molecular analysis is essential to confirm the diagnosis of Friedreich's ataxia; however, an adequate cardiac evaluation, including an electrocardiogram, was extremely useful to better screening the patients which should perform these molecular analysis.

Keywords: Friedreich's ataxia, cardiac abnormalities, hypertrophic cardiomyopathy.

Child's Institute of Hospital das Clínicas - FMUSP

Mailing address: Lilian M. J. Albano, Instituto da Criança, Hospital das Clínicas da FMUSP - Av. Dr. Enéas C. Aguiar, 647 - 05403-900 - São Paulo, SP - E-mail: lima@icr.hcnet.usp.br

Received for publication on $12 / 8 / 00$

Accepted on 4/18/01
Friedreich's ataxia ${ }^{1}$ is a progressive neurodegenerative disease and the commonest of all inherited ataxia, affecting the central and peripheral nervous system, bone and heart. It is characterized by a recessively inherited spinocerebellar degeneration with selective loss of large myelinated fibers in the dorsal root ganglia. Its incidence is approximately 1:50.000 and the carrier frequency is 1:70-110. The gene was mapped in $1988^{2}$ and, in 1996, it was cloned by Campuzano et al ${ }^{3}$.

Patients present a progressive gait ataxia and neurologic signals and symptoms occur in reason of the degeneration of dorsal root ganglia with loss of large sensory neurons, followed by thinning of the spinal cord due to atrophy of the posterior columns and spinocerebellar tracts. The onset of disease usually occur, in almost cases, before 25 years of age with a progressive ataxia, sensory loss and muscle weakness, often associated with scoliosis, pes cavus, hypertrophic cardiomyopathy. There is an increased risk of diabetes mellitus. It may also be present a neurosensorial deafness, nystagmus and optic atrophy. The disease leads to a progressive physical handicap at a young age and the most part of the patients are wheelchair bound at about 20 years of age. Currently, no treatment can delay the progression of the disease and, in general, survival is about 15 to 20 years after disease onset ${ }^{4}$.

The presence of hypertrophic cardiomyopthy, scoliosis and pes cavus is characteristic and it may be also associated to diabetes mellitus, in about $20 \%$ of cases ${ }^{5}$. Cardiac involvement is frequent, being over $90 \%$ in the Quebec's collaborative study and in other reports ${ }^{6-10}$.

\section{Methods}

We evaluate 25 patients in a prospective study between January 1997 and May 1999. They were selected from the reference charts or referred to the Genetics Unit of the Child Institute of the "Hospital das Clínicas", University of São Paulo as having Friedreich's ataxia, by one or more neurologists from the original service. Inclusion clinical criteria were those of Geoffroy et al ${ }^{11}$ and Harding ${ }^{4}$; however, cases in which deep tendon reflexes were present or that of onset after 25 years of age were not excluded. 
Patients and their family members were studied by means of a questionnaire (submitted to the Ethics Committee of the Department of Pediatrics and of the Hospital das Clínicas-FMUSP). Thereafter, a complete clinical investigation was performed and based on the pedigree analysis, other suspected relatives were identified and examined, as were unaffected first-degree relatives. The neurological evaluation of the selected patients was made together with the certified neurologists from de origin service.

Fast glucose blood test, oral glucose tolerance test, electrocardiogram, echocardiogram and cranial and/or spine computadorized tomography and the following evaluations were requested: cardiac, otolaryngologic and ophthalmologic, even without symptoms. The magnetic nuclear resonance and other subsidiary exams, relevant to each case and depending on its necessity, were also requested.

The results of clinical, neurological, laboratory, and molecular (frequency and size of GAA expansion - unstable expansion of trinucleotide repeats that results in the disease) evaluations were studied relate to the: age of onset and of wheelchair bound; presence of signals of cardiac abnormalities and/or abnormalities observed on the electrocardiogram, the echocardiogram, or both; presence of consanguinity and duration of the disease.

DNA extraction were performed at the Child's Institute of HC-FMUSP, from $10 \mathrm{ml}$ of whole blood leukocytes, as previously described by Miller, Dykes, Polesky ${ }^{12}$. The polymerase chain reaction was performed in the Laboratorio do Dipartimento de Patologia Cellulare e Molecolare-Universitá Federico II, Naples, Italy, according Filla et al ${ }^{13}$.

\section{Results}

Fifteen families were evaluated, involving 25 patients. Mean age of onset of the disease was $9,8 \pm 4,14$ years (varying from 2-18 years) and, after a mean length of 5,40 years (from the date of need for support to walking), the patients were wheelchair bound.

All cases with FRDA mutation who underwent electrocardiography (14/18) showed some abnormality and the commonest were those related to ventricular repolarization $(50 \%)$ (fig. 1). We also have observed: left ventricular hypertrophy, signals of ischemia, atrial tachycardia, auriculoventricular block, sinusal bradycardia and sinusal tachycar-

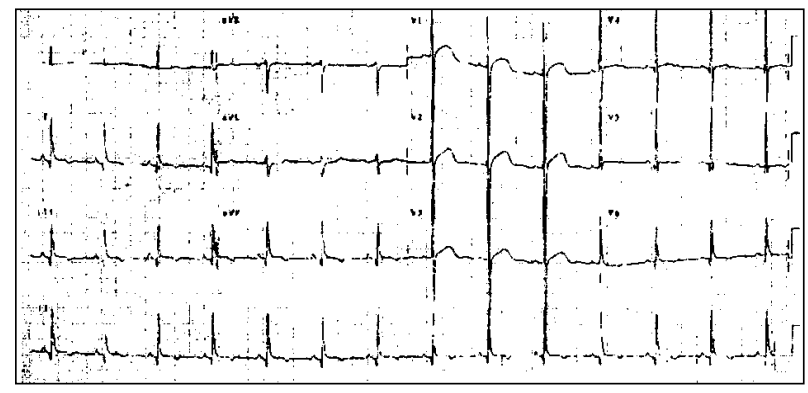

Fig. 1 - Electrocardiogram of one Friedreich's ataxia patient with ventricular repolarization abnormalities and ventricular hypertrophy. dia. On the other hand, only $25 \%$ of the cases without GAA expansion, presented some abnormality in the electrocardiogram.

Out of 17, only two patients of FRDA mutation presented some abnormality in echocardiogram $(2 / 9-22 \%)$, both with concentric ventricular hypertrophy.

The molecular analysis of 25 patients with a clinical diagnosis of Friedreich's ataxia revealed the FRDA mutation constituted by GAA homozygous expansion in $17 \mathrm{ca}-$ ses, confirming the diagnosis of Friedreich's ataxia in these patients. All of them presented abnormalities in ECG, but only $25 \%$ of patients without GAA expansion (not-Friedreich) presented some cardiac abnormality. These data attest the importance of performing a complete cardiac evaluation in Friedreich's ataxia, especially if we consider that only $6 \%(1 / 17)$ of the patients presented signals and/or symptoms of a cardiac involvement: auriculo flutter with variable block.

\section{Discussion}

In Friedreich's original report of 1863, one patient had died of typhoid fever with a fatty infiltration in the heart. Five of the 6 patients originally described by Friedreich had cardiac involvement and, in spite of Pitt (1887) and Saury (1905) had emphasized these features, they were unnoticed until Mollaret, in 1929, reported the electrocardiographic abnormalities present in the disease. Few studies were subsequently published about the cardiac abnormalities observed in Friedreich's ataxia and only in 1938 did Loiseau raise the possibility that this association was not merely casual. Thereafter, many reports were published in the European literature, especially by the French, who were more interest in the cardiac aspects of Friedreich's ataxia than were the Americans and British. Afterwards, it was realized that cardiac disturbances were, in fact, much more frequent than thought ${ }^{14,15}$.

Cardiomyopathy, usually in its hypertrophic form, is a cardinal feature ofFA. It is variable in its clinical and electric presentation and apparently, does not parallel the severity of other aspects of the disease (such as ataxia or muscle weakness). Although cardiomyopathy is typical of Friedreich's ataxia it is not exclusive of disease and maybe both, ataxia and miocardiopathy are manifestations of a common pathogenic defect, most probably inherited and biochemical in nature ${ }^{16}$.

Therefore, the cardiac disturbs in Friedreich's ataxia appear to be much more frequent than previously believed ${ }^{17-19}$ and it is accepted that the prominence of electrocardiographic defect parallels that of the neurologic deficit, in which the absent tendon reflexes in the lower extremities, extensor toe signs, scoliosis and pes cavus are most often correlated with electrocardiographic alterations ${ }^{14}$.

The main and more frequent clinical manifestations indicative of myocardial involvement are rhythm disturbances and myocardial insufficiency terminating in a congestive heart failure. These cardiac arrhythmias occur alone or in various combinations, including a complete heart block 
with Stokes-Adams syndrome. In general, patients do not exhibit any symptomatology. Breathlessness, paroxysmal tachycardia, palpitations and thoracic pain or discomfort, and respiratory movements with short amplitude have also been reported.

Cardiac enlargement when present, occurs late in the course of the illness. Anginal pain or decubitus angina has already been reported $(12 \%)$ and no correlation was found between this symptom and the coronarial changes sometimes described in some patients ${ }^{19-21}$. About $73 \%$ of the patients either died of heart failure or showed some clinical evidence of cardiac dysfunction during life. Of those who died with heart failure, it was demonstrated that $25 \%$ developed heart failure six months or more before death; and in $75 \%$ of them, the heart failure occurred only during the last six months of life ${ }^{22}$. Electrocardiographic abnormalities, observed in $75-100 \%$ of patients ${ }^{10,22-26}$, were more common in patients with absent tendon reflexes and extensor responses and, in general, these electrocardiographic alterations may precede neurological signs by many years. Often, severe electrocardiogram abnormalities may be found in asymptomatic patients ${ }^{6,20}$. In the present report, all typical patients with FRDA mutation presented electrocardiographic abnormalities in electrocardiogram, but only $25 \%$ of patients without GAA expansion and therefore, without Friedreich's ataxia, showed alterations in electrocardiogram (table I).

Therefore, the best indicator of myocardial involvement appeared to be the presence of electrocardiographic abnormalities. It may also help to establish the diagnosis of Friedreich's ataxia when the neurological manifestations are not altogether typical of the condition: an abnormal tracing lens support to the diagnosis, but a normal curve does not exclude it ${ }^{6,10}$.

Child et al ${ }^{27}$ found a normal electrocardiogram in only $8 \%$ of the cases and nonspecific ST-T wave changes were

\begin{tabular}{|c|c|c|c|}
\hline \multicolumn{4}{|c|}{$\begin{array}{l}\text { Table I - Abnormalities in electrocardiogram (ECG), echocardio- } \\
\text { gram (ECHO) and/or evidences of cardiac involvement in } \\
\text { Friedreich's ataxia ( \%), according to the literature }\end{array}$} \\
\hline References & $\begin{array}{c}\text { ECG } \\
\text { abnormalities al }\end{array}$ & $\begin{array}{l}\text { ECHO } \\
\text { bnormalities }\end{array}$ & $\begin{array}{c}\text { Cardiac } \\
\text { involvement }\end{array}$ \\
\hline Evans \& Wright $(1942)^{6}$ & $56 *$ & & \\
\hline Manning (1950) & 80 & & \\
\hline Boyer et al $(1962)^{18}$ & 55 & & 62 \\
\hline Heck $(1963)^{19}$ & & & 50 \\
\hline Hewer $(1968)^{22}$ & 90 & & 73 \\
\hline Berg (1980) & & 33 & 60 \\
\hline Campanella et al $(1980)^{24}$ & 75 & 50 & \\
\hline Pasternac et al $(1980)^{10}$ & 100 & 47 & \\
\hline Pentland \& Fox $(1983)^{30}$ & 82 & 41 & 82 \\
\hline Child et al $(1986)^{21}$ & 92 & 27 & \\
\hline Giunta et al $(1988)^{25}$ & 84 & 28 & \\
\hline Montermini et al (1997) & & & 82 \\
\hline Schöls et al (1997) & 83 & 75 & \\
\hline Present study (2001) & 100 & 22 & \\
\hline
\end{tabular}

the most common abnormality detected (75\%). They also detected: abnormally broad inferolateral Q waves (13\%), left ventricular hypertrophy (16\%), short PR interval (24\%), QRS axis with right axis deviation, tall right precordial $\mathrm{R}$ waves. Within a family some authors observed similar patterns of electrocardiographic changes ${ }^{6,19}$. Cardiac arrhythmias occurred in $50 \%$ of the fatal cases (Hewer) ${ }^{22}$ and atrial fibrilation occurred in $42 \%$ of them. ST-T wave changes were the most common abnormality observed (56-75\%) $)^{14,25-27}$.

Some authors have found severe electrocardiogram alterations in asymptomatic patients ${ }^{10}$. Our data were similar to the literature and only one typical patient with the FRDA mutation presented signals of cardiac involvement. He was hospitalized because of a palpitation and lately it was identified an atrial flutter with variable blockade.

The abnormalities in the echocardiogram were less frequent $(50-73 \%)^{10,24}$ and they are: asymmetric septal hypertrophy $(9 \%)$, concentric left ventricular hypertrophy $(11 \%)$, "dilated" cardiomyopathy, mitral valve prolapse, mitral valve motion for superior systolic displacement of the bellies of the leaflets and the coaptation point relative to the plane of the mitral anulus and for systolic anterior motion of the anterior mitral leaflet ${ }^{27}$. In the present study, two patients with FRDA mutation showed concentric ventricular hypertrophy (table I).

The cardiomyopathy in Friedreich's ataxia is almost ever represented by the concentric form. Asymmetric septal hypertrophy constitute the minor part, being the most part represented by the concentric hypertrophy, which can occur in mild forms or during the beginning of the disease. In the classical hypertrophic cardiomyopathy concentric hypertrophy is a rare event, presenting frequently an asymmetric septal hypertrophy. Hypertrophic cardiomyopathy shows familial transmission and it has also been observed dominant autosomal pattern of inheritance, whereas the cardiac involvement of Friedreich's ataxia does not have an independent transmission, being attached with neurologic abnormality ${ }^{10,25,28-30}$.

The combination of electrocardiography and echocardiography detected one or more abnormalities in $95 \%$ of the Child et al patients and it appears there are two fundamentally indifferent types of cardiac disease in Friedreich's ataxia: a) a common dystrophic form manifested by electrocardiographic initial force deformities without detectable echographic wall motion abnormalities, but occasionally by extension throughout the left ventricle with global hypokinesia and reduced QRS voltage; and b) a hypertrophic form represented by symmetric or asymmetric left ventricular hypertrophy with normal cavity size and ventricular function 27,28 .

In the present study, the definitive diagnosis of Friedreich's ataxia was established in $68 \%$ of the patients with a previous clinical diagnosis of Friedreich's ataxia (17/25) and in $89,5 \%$ of the typical cases $(17 / 19)$ that fulfilled the diseases's criteria ${ }^{4,11}$ - all with electrocardiographic abnormalities. On the other hand, only $25 \%$ of the patients without GAA expansion (not Friedreich) presented electrocardio- 
gram abnormalities. Therefore, it can be said that the definitive diagnosis of Friedreich's ataxia is only likely with molecular analysis. Nevertheless, a good clinical evaluation, including a complete cardiac evaluation or, at least an electrocardiogram, helps physicians to better screening the cases which should perform a molecular analysis.

Currently, one of the biggest advantages of a clear diagnosis of Friedreich's ataxia lies in the evidence of improvement in cardiac function and the therapeutic possibilities of acknowledging the neuroprotective effects of some substances with antioxidant properties ${ }^{31,32}$.

\section{Acknowledgments}

To the members of Laboratorio do Dipartimento de Patologia Cellulare e Molecolare - Universitá Federico II, Naples, Italy, specially to Dra. Antonella Monticelli and Dr Sergio Cocozza, to perform our molecular analysis. To Dra Telma Okay and Dr. Roberto Raíz Júnior of the Laboratory of Instituto da Criança, for performing the DNA extraction. To Dra. Maria Joaquina Marques-Dias, Dr. Fernando Kok, Dr. Sérgio Rosemberg, Dr. Lúcio Coelho Miranda, Dra. Maria Bernardete Dutra Resende, Dr. Ivan Ferrareto e Dr. Jorge David Aivazoglow Carneiro, for sending their patients.

\section{References}

1. OMIM - Online Mendelian Inheritance in Man, OMIM тм . Center for Medical Genetics, Johns Hopkins University (Baltimore, MD) and National Center for Biotechnology Information, National Library of Medicine (Bethesda, MD), 1996. Available at: http://www3.ncbi.nlm.nih.gov:80/htbin-post/Omim/ dispmim?229300.

2. Chamberlain S, Shaw J, Rowland A, et al. Mapping of mutation causing Friedreich's ataxia to human chromosome 9. Nat Genet 1988; 334: 248-50.

3. Campuzano V, Montermini L, Moltò MD, et al. Friedreich's ataxia: autosomal recessive disease caused by an intronic GAA triplet repeat expansion. Science 1996; 271: 1423-7.

4. Harding AE. Friedreich's ataxia: a clinical and genetic study of 90 families with an analysis of early diagnostic criteria and intrafamilial clustering of clinical features. Brain 1981; 104: 589-620.

5. Finocchiaro G, Baio G, Micossi P, Pozza G, Di Donato S. Glucose metabolism alterations in Friedreich's ataxia. Neurology 1988; 38: 1292-6.

6. Evans W, Wright G. The electrocardiogram in Friedreich disease. Br Heart J 1942; 4: 91-9.

7. Thorén C. Diabetes mellitus in Friedreich's ataxia. Acta Paediatr (Stockholm) 1962; 135(suppl): 239-47.

8. Hewer RL. The heart in Friedreich's ataxia. Br Heart J 1969; 31: 5-14.

9. Malo S, Latour Y, Cote M, Geoffroy G, Lemieux B, Barbeau A. Electrocardiographic and vectocardiographic findings in Friedreich's ataxia. Can J Neurol Sci 1976; 3: 323-8.

10. Pasternac A, Król, R, Petitclerc R, Harvey C, Andermann E, Barbeau A. Hypertrophic cardiomyopathy in Friedreich's ataxia: symmetric or ou asymmetric? Can J Neurol Sci 1980; 7: 379-82.

11. Geoffroy G, Barbeau A, Breton G, et al. Clinical description and roentgenologic evaluation of patients with Friedreich's ataxia. Can J Neurol Sci 1976; 3: 279-86.

12. Miller SA, Dykes DD, Polesky HF. A simple salting out procedure for extracting DNA from human nucleated cells. Nucleic Acids Res 1988; 6: 1215.

13. Filla A, De Michele G, Cavalcanti F, Pianese L, Monticelli A, Campanella G. The relationship between trinucleotide (GAA) repeat length and clinical features in Friedreich ataxia. Am J Hum Genet 1996; 59: 554-60.

14. AlbanoLMJ.Estudomoleculardeportadores deataxiadeFriedreich. TesedeDoutorado Faculdade de Medicina da Universidade de São Paulo. São Paulo, 2000.

15. Albano LMJ. Genética clínica e molecular das doenças neurológicas com mutações dinâmicas. São Paulo: Manole, 2000: 185p.

16. Barbeau A. The Quebec cooperative study of Friedreich's ataxia: 1974-1984 - 10 years of reasearch. Can J Neurol Sci 1984b; 11(suppl): 646-60.

17. Hartman JM, Booth RW. Friedreich's ataxia: a neurocardiac disease. Am Heart J 1960; 60: 716-20.

18. Boyer SH, Chisholm AW, McKusick VA. Cardiac aspects of Friedreich's ataxia Circulation 1962; 25: 493-505.
19. Heck AF. Heart disease in Friedreich's ataxia: clinical studies and review of the literature (part I). Neurology 1963; 13: 587-95.

20. Flipse ME, Dry TJ, Woltman HW. The heart in Friedreich's ataxia. Minnesota Med 1950; 33: 1000-03.

21. Salisachs P. La historia natural de la enfermedad de Friedreich: a proposito de 13 casos. Med Clin 1974; 63: 1-10.

22. Hewer RL. Study of fatal cases of Friedreich's ataxia. Br Med J 1968b; 3: 649-52.

23. AndermannE, Remillard GM, GoyerC, Blitzer L, AndermannF, Barbeau A. Genetic and family studies in Friedreich's ataxia. Can J Neurol Sci 1976; 3: 287-301.

24. Campanella G, Filla A, De Falco F, Mansi D, Durivage A, Barbeau A. Friedreich's ataxia in the south of Italy: a clinical and biochemical survey of 23 patients. Can J Neurol Sci 1980; 7: 351-7.

25. Giunta A, Maione S, Biagini R, Filla A, De Michele G, Campanella G. Noninvasive assesment of systolic and diastolic function in 50 patients with Friedreich's ataxia. Cardiology 1988; 75: 321-7.

26. Filla A, De Michele G, Caruso G, Marconi R, Campanella G. Genetic data and natural history of Friedreich's disease: a study of 80 Italian patients. J Neurol 1990; 237: 345-51.

27. Child JS, PerloffJK, Bach PM, Wolfe AD, Perlman S, Kark P. Cardiac involvement in Friedreich's ataxia: a clinical study of 75 patients. J Am Coll Cardiol 1986; 7 : 1370-8.

28. Pellicelli AM, Borgia C, Ferranti E, et al. Caratteristiche anatomo-cliniche ed ecocardiografiche della cardiopatia in corso di atassia di Friedreich: descrizione di un caso clinico. G Ital Cardiol 1994; 24 : 47-51.

29. D'Angelo A, Di Donato S, Negri G, et al. Friedreich's ataxia in northern Italy: I. Clinical, neurophysiological and biochemical studies. Can J Neurol Sci 1980; 7 : 359-65.

30. Pentland B, Fox KAA. The heart in Friedreich's ataxia. J Neurol Neurosurg Psychiatr 1983; 46: 1138-42.

31. ShulzJB, Dehmer T, Schöls L, et al. Oxidative stress in oxidative stress in patients with Friedreich's ataxia. Neurology 2000; 55: 1719-21.

32. Sherer T, Greenamyre JT. A therapeutic target and biomarker in Friedreich's ataxia Neurology 2000; 55: 1600-1.

33. Manning GW. Cardiac manifestations in Friedreich's ataxia. Am Heart J 1950; 39: 799-816.

34. Berg RA, Kaplan AM, Jarrett PB, Molthan ME. Friedreich's ataxia with acute cardiomyopathy. Am J Dis Child 1980; 134: 390-3.

35. Montermini L, Richter A, Morgan K, et al. Phenotypic variability in Friedreich ataxia role of the associated GAA triplet repeat expansion. Ann Neurol 1997; 41: 675-82.

36. Schöls L, Amoiridis G, Przuntek H, Frank G, Epplen JT, Epplen C. Friedreich's ataxia: revision of the phenotype according to molecular genetics. Brain 1997; 120: $2131-40$ 